\title{
Understanding brain dysfunction in sepsis
}

\author{
Romain Sonneville ${ }^{1,2}$, Franck Verdonk ${ }^{2}$, Camille Rauturier ${ }^{2}$, Isabelle F Klein ${ }^{3}$, Michel Wolff' ${ }^{1}$ Djillali Annane ${ }^{4}$, \\ Fabrice Chretien ${ }^{2}$ and Tarek Sharshar ${ }^{2,4^{*}}$
}

\begin{abstract}
Sepsis often is characterized by an acute brain dysfunction, which is associated with increased morbidity and mortality. Its pathophysiology is highly complex, resulting from both inflammatory and noninflammatory processes, which may induce significant alterations in vulnerable areas of the brain. Important mechanisms include excessive microglial activation, impaired cerebral perfusion, blood-brain-barrier dysfunction, and altered neurotransmission. Systemic insults, such as prolonged inflammation, severe hypoxemia, and persistent hyperglycemia also may contribute to aggravate sepsis-induced brain dysfunction or injury. The diagnosis of brain dysfunction in sepsis relies essentially on neurological examination and neurological tests, such as EEG and neuroimaging. A brain MRI should be considered in case of persistent brain dysfunction after control of sepsis and exclusion of major confounding factors. Recent MRI studies suggest that septic shock can be associated with acute cerebrovascular lesions and white matter abnormalities. Currently, the management of brain dysfunction mainly consists of control of sepsis and prevention of all aggravating factors, including metabolic disturbances, drug overdoses, anticholinergic medications, withdrawal syndromes, and Wernicke's encephalopathy. Modulation of microglial activation, prevention of blood-brain-barrier alterations, and use of antioxidants represent relevant therapeutic targets that may impact significantly on neurologic outcomes. In the future, investigations in patients with sepsis should be undertaken to reduce the duration of brain dysfunction and to study the impact of this reduction on important health outcomes, including functional and cognitive status in survivors.
\end{abstract}

Keywords: Delirium, Brain dysfunction, Sepsis

\section{Review}

Sepsis often is characterized by an early and acute encephalopathy, which is associated with increased morbidity and mortality [1,2]. Patients present with fluctuating mental status changes, inattention, disorganized thinking and therefore match with current criteria for delirium. Delirium is a multifactorial syndrome and several risk factors have been identified during critical illness, including patients' characteristics (e.g., older age, cognitive impairment), the severity of illness, environmental factors (e.g., sleep deprivation, noisy environment), medications (e.g., benzodiazepines, opioids), and common metabolic disturbances, such as fever, dysnatremias, hypoglycemia, and possibly hyperglycemia [3-5]. Among the myriad of conditions that can induce

\footnotetext{
* Correspondence: tarek.sharshar@rpc.aphp.fr

${ }^{2}$ Histopathologie Humaine et Modèles Animaux, Département Infection et Epidémiologie, Institut Pasteur, Paris, France

${ }^{4}$ Réanimation medico-chirurgicale et EA4342, Hôpital Raymond Poincaré,

Université de Versailles Saint-Quentin en Yvelines, Garches, France

Full list of author information is available at the end of the article
}

delirium in critical illness, sepsis, in the form of sepsisassociated encephalopathy (SAE), represents the most frequent and severe cause [6,7]. Diagnosing brain dysfunction in a patient with sepsis implies a systematic diagnostic approach of all potential factors, in addition to sepsis, that can contribute to aggravate or prolong brain dysfunction. The purpose of this review is to provide an overview of brain dysfunction in sepsis focusing on pathophysiology, diagnosis, and potential strategies to improve neurologic outcomes.

\section{Pathophysiology}

Brain signaling and microglial activation

The encephalopathy in sepsis is considered a diffuse cerebral dysfunction as a consequence of the systemic inflammatory response to an infection, with no direct central nervous system infection (Figure 1). The response to stress is physiologically triggered by an activating signal that is mediated by two pathways. The first one is the vagus nerve, which can detect visceral

\section{实}




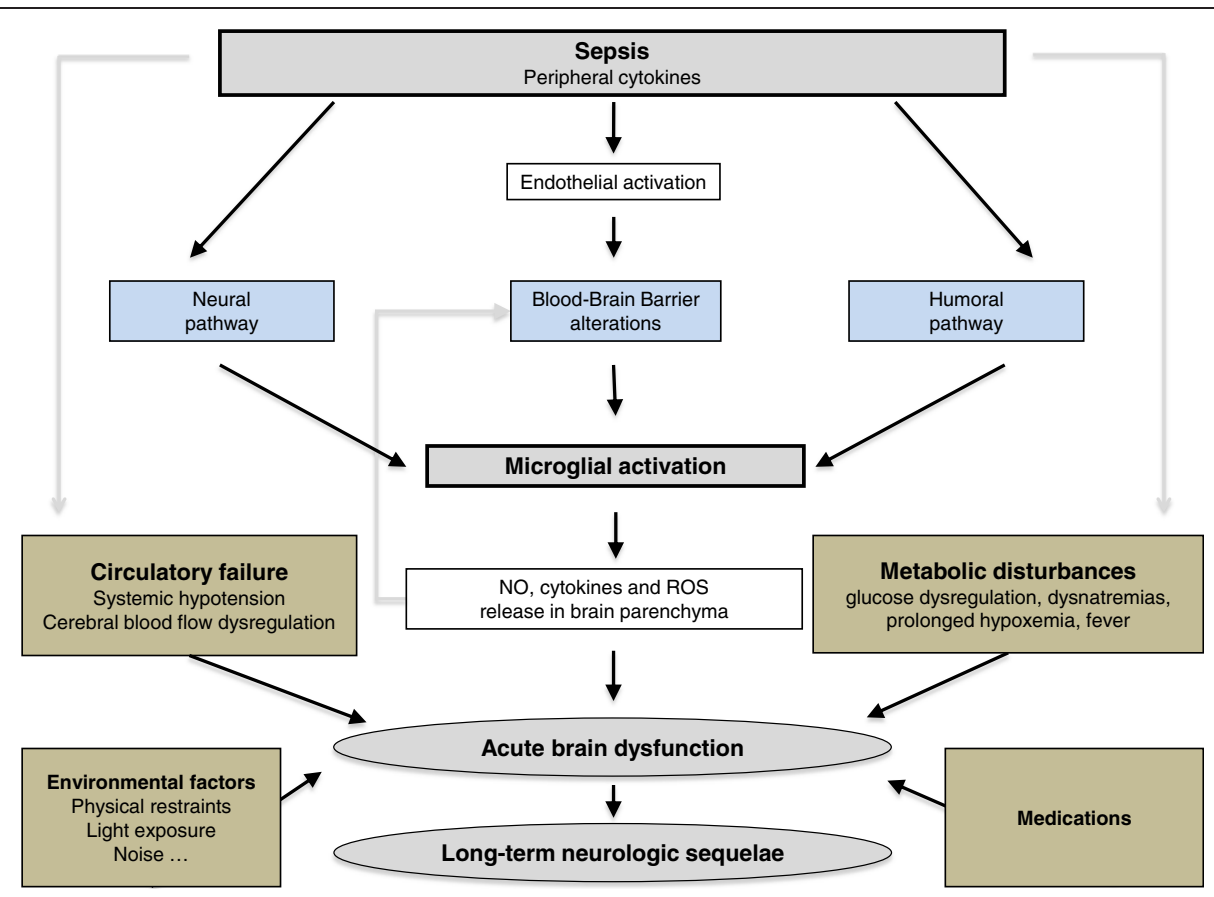

Figure 1 The response of the brain to systemic infection is physiologically triggered by an activating signal that is mediated by three pathways. 1) The neural pathway that requires activation of primary afferent nerves, such as the vagal or the trigeminal nerves, by involving peripherally produced pathogen-associated molecular patterns (PAMPs) and cytokines. 2) The humoral pathway involves circulating cytokines. They reach the brain at the level of the choroid plexus and the circumventricular organs that lie outside the blood-brain barrier (BBB). 3) The blood-brain barrier alterations induced by the activation of cerebral endothelial cells results in the release of various mediators into the brain. This activation is due to the production, at the early phase of sepsis, of nitric oxide synthase-derived nitric oxide. All of these pathways instigate the activation of microglial cells, which are the resident immune cells of the brain. When activated, microglial cells may negatively affect the brain by the production of nitric oxide, cytokines, and reactive oxygen species that lead to cell death within vulnerable areas of the brain. This production is, in itself, responsible for an increase of the BBB alterations, thus causing a vicious circle of increasing brain dysfunction and injury. These mechanisms are compounded by common metabolic disturbances that occur in septic patients (such as prolonged hyperglycemia, severe hypoxemia), hemodynamic failure, use of medications, and iatrogenic and environmental factors. Septic-associated brain dysfunction may be associated with neurologic sequelae in survivors, including functional and cognitive decline, probably by neurodegenerative and/or ischemic mechanisms.

inflammation through its axonal cytokines receptors: inflammatory products produced in damaged tissues activate afferent signals that are relayed to the nucleus tractus solitarius in the brainstem. Subsequent activation of vagus efferent activity inhibits cytokine synthesis in damaged tissues through a cholinergic anti-inflammatory pathway (the inflammatory reflex) [8]. The vagus nerve is also connected to other autonomic nuclei, notably the paraventricular nucleus that controls adrenal axis and vasopressin secretion [9]. The second pathway involves the circumventricular organs (CVOs), which are located near neuroendocrine and neurovegetative nuclei. CVOs are deprived of a blood-brain barrier (BBB) and express components of innate and adaptive immune systems. Once visceral or systemic inflammation is detected by the first or the second pathway, the activating signal will spread to behavioral, neuroendocrine, and neurovegetative centers. Sepsis enhances the transcription of several pro- and antiinflammatory cytokines and chemokines in the brain, including tumor necrosis factor alpha (TNF $\alpha$ ), interleukin-1 beta (IL1 $\beta$ ), transforming growth factor beta (TGF $\beta$ ), and monocyte chemoattractant protein 1 (MCP1) [10]. These mediators modulate the expression of $\alpha$-amino-3-hydroxy5-methyl-4-isoxazolepropionic acid receptors (AMPARs) and N-methyl-D-aspartate receptors (NMDARs) on neurons, inducing brain dysfunction [11]. Recent studies have suggested the novel importances of IL1 $\beta$ and High Mobility Group Box 1 on the development of cognitive impairment in sepsis survivors $[12,13]$. These cytokines also modulate NMDARs, with functional consequences on cognition and behavior [14].

Microglial activation may represent one of the earliest changes observed in sepsis-associated encephalopathy and prolonged microglial activation may negatively affect other brain cells [15]. Early microglial activation in sepsis was evidenced in mice models within 4 hours following LPS injection, as assessed by the increased proinflammatory cytokine IL1 $\beta$ level in microglia [16]. Using Positron Emission Tomography (PET) imaging in nonhuman primates, another study demonstrated 
microglia activation only $1 \mathrm{~h}$ after LPS-induced systemic inflammation [17]. Moreover, experimental studies suggest that aging may increase the intensity of microglial activation and the production proinflammatory cytokines in the hippocampus, notably IL1 $\beta[18,19]$. The IL1 $\beta$-mediated inflammatory process in the hippocampus was confirmed in different models of systemic inflammation, including cecal ligation and puncture and peripheral surgery $[20,21]$. Numerous experimental studies suggest that these proinflammatory mediators released in the central nervous system at the onset of sepsis will in turn lead to neuronal loss within vulnerable areas of the brain, including the hippocampus [22-24]. Collectively, these findings represent a neuropathological basis for persistent cognitive impairment, hippocampal atrophy, and electroencephalographic changes observed in sepsis survivors [25].

\section{Endothelial activation and blood-brain barrier dysfunction}

Sepsis induces activation of cerebral endothelial cells, which result in $\mathrm{BBB}$ dysfunction and release of various mediators into the brain. Experimental data indicate that at the early phase of sepsis, endothelial nitric oxide synthase-derived nitric oxide exhibits proinflammatory characteristics and contributes to the activation and dysfunction of cerebrovascular endothelial cells [26]. The activated endothelium relays the inflammatory response into the brain by releasing proinflammatory cytokines and NO that are able to interact with surrounding brain cells. The other consequences of endothelial activation may include microcirculatory dysfunction, which might compromise cerebral perfusion [27]. Other studies suggest that endotoxemia leads to inflammation in brain, with alteration in BBB, up-regulation of aquaporin 4 (AQP4) and associated edema, neutrophil infiltration, astrocyte activation, as well as apoptotic cell death, all of which appear to be mediated by TNF-alpha signaling through TNF-receptor 1 [28]. Alterations of BBB also have been evidenced in patients with septic shock, with help of brain MRI [29]. BBB breakdown can be localized in the cortex around the Virchow-Robin spaces or have a more diffuse pattern in the whole white matter. It also can predominate in posterior lobes, being consistent with a posterior reversible encephalopathy syndrome [30]. Noninvasive assessment by MRI allowed the identification of new aspects of brain damage in experimental models of sepsis, including cytotoxic and vasogenic edema as well as neuronal damage. These findings highlight the potential applications of MRI techniques for the diagnostic and therapeutic studies in sepsis [31]. Finally, $\mathrm{BBB}$ alterations might facilitate the passage of potential neurotoxic factors from the peripheral circulation to the brain. For instance, plasma tryptophan levels are associated with delirium in critically ill patients [32,33]. More recently, increased kynurenine pathway activation, assessed by plasma kynurenine and kynurenine/tryptophan ratio, was found to be associated with fewer days without acute brain dysfunction [33].

Endothelial activation alters vascular tone and induces both microcirculatory dysfunction and coagulopathy, which will in turn favor ischemic and/or hemorrhagic lesions [34]. Neuropathological studies performed in nonsurvivors of septic shock suggest that ischemia is consistently observed in brain areas susceptible to low cerebral flow and that hemorrhages can be found in approximately $10 \%$ of cases $[34,35]$. Furthermore, it has been recently shown that SAE is rather associated with disturbed autoregulation than with altered cerebral blood flow or tissue oxygenation [36].

\section{Deficit in cholinergic function and alteration of neurotransmission}

Deficits in cholinergic function have been postulated to cause delirium and cognitive decline [37]. Global hypocholinergia result from several mechanisms, including impaired acetylcholine synthesis and cholinergic synaptic dysfunction (impairment of presynaptic, synaptic, or postsynaptic functions of acetylcholine). Nicotinic receptors within the brain bind acetylcholine to modulate cognitive functioning, arousal learning, and memory. Use of anesthetic drugs that decrease acetylcholine release (e.g., isoflurane) may impact on cognitive function after surgery [38]. Anticholinergic medications and their metabolites also may induce delirium through competitive antagonism of postsynaptic muscarinic receptors that are more widely distributed throughout the brain. It was recently demonstrated that chronic cholinergic hypoactivity in the basal forebrain represents a major factor of acute brain dysfunction under systemic inflammation [39].

Other significant neurotransmitter alterations have been described during experimental sepsis, involving brain beta-adrenergic, gamma-aminobutyric acid, and serotoninergic pathways [40]. These phenomena seem to predominate in cortex and in hippocampus, and may be mediated by NO, cytokines and prostaglandins [41]. Neurotransmitter balance also is altered by different circulating molecules, such as ammonium, tyrosine, tryptophan, and phenylalanine, whose plasma levels are increased secondary to liver dysfunction and muscle proteolysis [42]. Imbalance between dopaminergic and cholinergic neurotransmission is considered a major mechanism of delirium in critically ill patients. It also has been hypothesized that reduced cholinergic inhibition of microglia is involved in delirium [15]. However, administration of rivastigmine, a pharmacological agent that may restore cholinergic control of microglia, did 
not decrease duration of delirium and might have increased mortality of critically ill patients with delirium [43]. Data from studies performed in critically ill patients receiving prolonged mechanical ventilation also suggest that use of GABA-agonists, such as benzodiazepines, is associated with an increased risk of brain dysfunction [44]. Noradrenergic neurotransmission also might be particularly involved in SAE as dexmedetomidine, a selective agonist of alpha2-adrenoceptors expressed in the locus coeruleus, is associated with less brain dysfunction and better outcomes in septic patients compared with midazolam $[45,46]$. These findings were recently confirmed in a recent, multicenter trial, where dexmedetomidine compared with midazolam, improved patient's ability to communicate [47]. Beneficial effects of dexmedetomidine notably include significant preconditioning and postconditioning effects against ischemic brain injury $[48,49]$. More recent experimental data suggested that neuroprotective effects of dexmedetomidine against glutamate-induced cell death were mediated by an increase in astrocyte expression of brain-derived neurotrophic factor through an extracellular signal-regulated kinase-dependent pathway [50].

\section{Oxidative stress, mitochondrial dysfunction, and apoptosis}

Experimental data suggest that oxidative damage, assessed by the thiobarbituric acid reactive species and the protein carbonyl assays, occurs early (after 6 hours) in the course of sepsis [51]. Moreover, the combined use of antioxidants (N-acetyl-cysteine and deferoxamine) attenuates oxidative damage in hippocampus 6 hours after sepsis induction [52]. Mitochondrial-mediated apoptosis has been evidenced in experimental sepsis and might be related to a decrease of intracellular anti-apoptotic (bcl-2) and an increase of pro-apoptotic (bax) factors [22]. In patients who had died from septic shock, neuronal and microglial apoptosis have been detected in neurovegetative and neuroendocrine nuclei as well as in amygdala [35]. Intensity of apoptosis correlated with expression of endothelial iNOS. Recent data suggested that Caspase-3 is involved in part in apoptosis in the dentate gyrus cell layer of the hippocampus in septic rats [53]. Additionally to nitric oxide, other pro-apoptotic factors have been incriminated, such as glutamate, TNF $\alpha$, and hyperglycemia [54].

\section{Prolonged inflammation and other systemic insults}

A recent study performed in critically ill patients suggested that high baseline inflammatory biomarkers of systemic inflammation at admission, such as C-reactive protein and procalcitonin, predicted prolonged periods of acute brain dysfunction, irrespective of whether patients had sepsis or not [55]. In another study performed in 50 patients with systemic inflammatory response syndrome (SIRS), IL-8 was independently associated with delirium [56]. These findings suggest that sustained systemic inflammation may contribute to prolong or aggravate brain dysfunction. Stress hyperglycemia, which commonly develops in critically ill patients, also may aggravate sepsis-induced brain injury. In a recent neuropathological study performed in nonsurvivors of critical illness, hyperglycemia was shown to aggravate critical illness-induced neuropathological changes [57]. Patients with uncontrolled hyperglycemia showed increased microglial activation, an important reduction in the density and activation status of astrocytes, increased neuronal damage, and apoptosis in hippocampus and frontal cortex. Most of these abnormalities were virtually absent with normoglycemia. Interestingly, moderate hyperglycemia was shown to be associated with adverse cognitive outcomes in survivors of the acute respiratory distress syndrome [58]. Prolonged hypoxemia also may contribute to brain dysfunction and injury during sepsis. Recently, in a study performed in survivors of prolonged critical illness, a low partial pressure of arterial oxygen during ICU stay was associated with cognitive and psychiatric impairment at 12 months [59].

\section{Selective vulnerability}

Brain lesions in septic shock have been described in areas of the brain susceptible to ischemia (including Ammon's horn, the frontal junctional cortex, the lenticular nuclei, the dentate nucleus, and the medullary olive), in the hypothalamic nuclei (supraoptic and paraventricular nuclei), the amygdala, the locus coeruleus, and the medullary autonomic nuclei (nucleus tractus solitarii, ambiguous, and parabrachial nuclei) $[34,35]$. Hippocampal lesions due to inflammatory but also ischemic, hypoxic, or dysglycemic insults $[57,60]$ may explain long-term psychological and cognitive disorders observed in survivors of critical illness $[25,61]$. Interestingly, reduction of oxidative stress in hippocampus is associated with less cognitive dysfunction in septic rats [52]. There also are arguments for a global brainstem dysfunction during sepsis. First, a recent study suggested that abolition of cough reflex and oculocephalic responses in sedated critically ill patients are associated with death and delirium, respectively [62]. Second, the brainstem nuclei are liable to apoptosis [35] and use of dexmedetomidine, which have antiapoptotic properties [63], is associated with less delirium in septic patients [64]. Finally, impaired sympathetic control of heart rate is frequent and associated with increased mortality in septic patients suggesting a central autonomic regulatory dysfunction [65]. 


\section{Diagnosis}

\section{Clinical examination}

\section{Clinical examination}

Detection of acute brain dysfunction in ICU is based on repeated daily neurological examination. Sepsis-associated encephalopathy is characterized by acute changes in mental status, cognition, alteration of sleep/wake cycle, disorientation, impaired attention, and/or disorganized thinking [66]. Sometimes exaggerated motor activity with agitation, and/ or hallucinations can be observed and agitation and somnolence can occur alternatively. Other but less frequent motor symptoms include paratonic rigidity, asterixis, tremor and multifocal myoclonus. Physicians have at their disposal validated clinical instruments for detecting brain dysfunction of critically ill patients, including the Confusion Assessment Method for the ICU (CAM-ICU) [6], and the intensive care delirium screening checklist (ICDSC) [67]. Once brain dysfunction is identified, an exhaustive neurological examination assessing neck stiffness, motor responses, muscular strength, plantar and deep tendon reflexes and cranial nerves is mandatory. Although the use of sedative drugs may represent a major limitation in the interpretation of clinical findings, a recent study suggested that assessment of brainstem responses is feasible in sedated critically ill patients and loss of selected responses is predictive of mortality and altered mental status [62]. Assessments of plasma levels of brain injury biomarkers, such as neuron specific enolase and S-100 B-protein, have been proposed for detecting brain dysfunction and injury in sedated patients with sepsis $[68,69]$. Occurrence of sudden fluctuations in mental status unexplained by modification of sedative infusion rate, occurrence of focal neurological sign, seizure(s) and/or neck stiffness should prompt the physician to consider neuroimaging, EEG and/or lumbar puncture to rule out a direct central nervous system infection.

\section{Brain imaging}

In case of focal neurological signs, a brain computed tomography should be performed to rule out ischemic or hemorrhagic brain injury [29,34]. Brain MRI should be considered systematically in case of persistent encephalopathy after control of sepsis and exclusion of major confounding factors. With use of diffusionweighted imaging and gradient echo sequences, this tool has a higher sensitivity than CT for detecting acute CNS disorders, such as recent ischemic or hemorrhagic stroke. Several changes have been described in septic patients (Table 1). Moreover, additionally to the importance of etiological diagnosis, assessment of the nature, and extent of brain damage may also influence patient's treatment.
Table 1 Brain MRI patterns in sepsis

\begin{tabular}{|c|c|}
\hline Brain MRI findings & References \\
\hline \multicolumn{2}{|l|}{ Acute changes } \\
\hline Cytotoxic edema (hippocampus, cortex) ischemic lesions & {$[29,31]$} \\
\hline Vasogenic edema & {$[29,31]$} \\
\hline Posterior reversible encephalopathy syndrome (PRES) & {$[30,70]$} \\
\hline \multicolumn{2}{|l|}{ Chronic changes observed in survivors } \\
\hline White matter disruption & {$[71]$} \\
\hline Brain atrophy & {$[25,72]$} \\
\hline (frontal cortex, hippocampus) & \\
\hline
\end{tabular}

\section{Electroencephalography}

In case of seizure(s), including palpebral myoclonus, an EEG will be required to rule out subtle status epilepticus. Several electrographic patterns have been described in septic patients (Table 2). Sepsis can be associated with electrographic seizures or periodic epileptiform discharges [73]. In a recent study, generalized periodic discharges were strongly associated with nonconvulsive seizures and nonconvulsive status epilepticus [74]. However, the impact of generalized periodic discharges on neurologic outcomes remains to be elucidated. Other EEG abnormalities include increased theta rhythms, triphasic waves and, less often but more pejorative, burst suppression patterns [75].

\section{Causes of encephalopathy requiring specific treatment}

Standard laboratory tests should be performed systematically to detect and correct common metabolic disturbances that can cause delirium or coma (such as hypoglycemia, hypercalcemia, hypo- or hypernatremia). In addition to sedatives and analgesics, many classes of drugs currently administered in critically ill patients can induce acute brain dysfunction, notably a number of antibiotics, steroids, and cardiac drugs (Table 3).

Benzodiazepines and opioid withdrawal syndromes may represent an important cause of delirium after discontinuation of sedation. Alcohol withdrawal syndrome often is evoked in a patient with a history of alcohol dependence who develops encephalopathy [78]. The predominance of psychomotor agitation and autonomic signs are suggestive of the diagnosis. The benefit of alcohol withdrawal prophylaxis is unproven. Early and aggressive titration of medication guided by symptoms is the only feature associated with improved outcomes. In malnourished or alcoholic patients, Wernicke's encephalopathy must always be evoked and treated with intravenous thiamine, especially if there is evidence of ophthalmoplegia or ataxia [79]. Thiamine deficiency can be aggravated by infusion of glucose. Tobacco dependency is a risk factor for delirium in critically ill patients, which may be prevented by use of nicotine patch in 
Table 2 Electroencephalographic patterns in sepsis

\begin{tabular}{llll}
\hline Electroencephalographic findings & Association with adverse outcome & References \\
\hline Normal EEG & 0 & {$[76]$} & {$[76]$} \\
Theta (mild generalized slowing) & + & + & {$[76]$} \\
Delta (severe slowing) & + & {$[76]$} & {$[73,74,77]$} \\
Triphasic waves & + & ++ & {$[73]$} \\
Periodic epileptiform discharges & ++++ & {$[75,76]$} \\
Electrographic seizures & + & \\
Generalized suppression or burst-suppression & &
\end{tabular}

chronic smokers [80]. Numerous iatrogenic and/or environmental factors also may aggravate brain dysfunction, such as use of physical restraints, excessive noise, or underexposure to light in the ICU $[81,82]$.

In a patient with unexplained neurologic symptoms (focal neurologic sign or encephalopathy) and bloodstream infection, infective endocarditis should be systematically ruled out as this condition often is associated with neurologic complications [83]. Of note, endocarditis has to be ruled out in the presence of cerebral microbleeds on MRI [84]. Finally, air embolism is an iatrogenic cause of sudden coma, agitation, seizure, or focal neurological signs, and for which hyperbaric oxygen is recommended. It must be emphasized that SAE often is a multifactorial condition.

Table 3 Medications associated with brain dysfunction in the ICU

\begin{tabular}{|c|c|}
\hline Agent & Mechanism of action \\
\hline Benzodiazepines & CNS sedation, neuronal inhibition by membrane hyperpolarization (GABA-agonist) \\
\hline \multicolumn{2}{|l|}{ (long- and short-acting) } \\
\hline Opioids & Anticholinergic toxicity, CNS sedation, fecal impaction \\
\hline Antibiotics & Inhibition of GABA-A receptors \\
\hline \multicolumn{2}{|l|}{$\begin{array}{l}\text { Penicillins, cephalosporins, carbapenems, } \\
\text { Quinolones }\end{array}$} \\
\hline Antiarrhythmics & Strong anticholinergic effects, sodium channel blockage, unknown \\
\hline \multicolumn{2}{|l|}{ Flecaïne, Amiodarone, Digoxin } \\
\hline Beta-blockers & Not yet described, association with delirium \\
\hline Diuretics & Dehydration and electrolyte disturbances \\
\hline Steroids & $\begin{array}{l}\text { Anticholinergic toxicity, Increase of catecholamine activity, GABA-agonist, altered serotonin } \\
\text { activity }\end{array}$ \\
\hline Inhaled anesthetics & Beta-amyloïd protein generation, cytotoxicity of beta-amyloïd potentiating, apoptosis-inducing \\
\hline Ketamine & NMDA-antagonism \\
\hline Histamine-2 blocking agents & Anticholinergic toxicity \\
\hline \multicolumn{2}{|l|}{ Cimetidine } \\
\hline Nonsteroidal anti-inflammatory drugs & Blood-brain-barrier permeability \\
\hline Anticholinergics & Anticholinergic toxicity \\
\hline \multicolumn{2}{|l|}{ oxybutynin, bladder antispasmodics } \\
\hline Anticonvulsants & CNS Sedation \\
\hline \multicolumn{2}{|l|}{ phenobarbital, phenytoin } \\
\hline Antiparkinsonian agents & Dopaminergic toxicity \\
\hline \multicolumn{2}{|l|}{ L-Dopa, dopamine agonists, amantadine } \\
\hline Antidepressants & Anticholinergic toxicity \\
\hline (amitriptyline, imipramine, doxepin) & \\
\hline
\end{tabular}

CNS central nervous system. 
Finally, reappearance or persistence of encephalopathy may indicate that sepsis is not controlled.

\section{Outcomes}

Eidelman et al. showed in a landmark study that approximately one-third of patients with sepsis had a Glasgow coma scale less than 12 and that alteration of alertness and consciousness was an independent prognosis factor, increasing mortality rate up to $63 \%$ when Glasgow coma scale drops below 8 [1]. More recent studies have shown that in addition to being highly prevalent in the ICU, delirium is an independent risk factor for threefold increase in mortality, with elderly patients being at an increased risk [7]. Number of days of ICU delirium was associated with higher 1-year mortality after adjustment for relevant covariates in an older ICU population [85]. Mortality also increases with severity of electrophysiological abnormalities, ranging from 0 when EEG is interpreted as normal to $67 \%$ when it shows burst suppressions [73,76]. Electrographic seizures and periodic discharges also are associated with increased mortality [29,73-75]. The prognosis value of MRI findings remains to be assessed [29]. The impact of brain dysfunction during sepsis on secondary outcomes is not known but is certainly close to that reported for delirium in critically ill patients, including prolonged length of stay in ICU and hospital, a longer duration of mechanical ventilation and at an extra cost $[7,86]$. Severe sepsis also is independently associated with substantial and persistent new cognitive impairment and functional disability [87]. A cognitive deficit also has been reported in survivors from the acute respiratory distress syndrome [88-90]. Interestingly, it has been shown that an elevated level of amyloid-beta in intensive care patients with delirium correlates with long-term cognitive impairment [56]. In addition, hippocampal atrophy may represent a determinant of neuropsychological sequelae [25], including depression, anxiety, and posttraumatic stress syndrome [91].

\section{Therapeutic perspectives}

Because there is no specific treatment for SAE yet, treatment should focus on control of infection source and supportive measures, such as management of organ failure(s), prevention of metabolic disturbances, and avoidance of neurotoxic drugs. Preventive strategies to reduce occurrence and duration of brain dysfunction should be applied for every patient admitted to the ICU (Table 4). Symptomatic treatment of delirium and agitation does not differ from that propose in critically ill patients and has been described elsewhere [92]. Adjunctive therapies of septic shock may protect the BBB or reduce endothelial activation, but their effect has not been established. For instance, activated protein $C$ in septic shock patients with impaired consciousness significantly reduced plasma levels of S100- $\beta$ protein [93]. Steroids have been shown to reduce posttraumatic stress syndrome [94] and prevention of prolonged hyperglycemia also may be neuroprotective [57].

Various therapeutic interventions have been experimentally tested. Inhibition of iNOS reduces neuronal apoptosis in septic animals but does not improve the state of consciousness and may even aggravate ischemic injuries of the brain [105]. Another study showed that sepsis-induced cognitive impairment at 2 months was prevented in iNOS knockout mice [24]. Experimental studies show a protective effect on the BBB with the use of magnesium [106,107], riluzole [107], hyperbaric oxygen therapy [108], calcium channel blockers, steroids, or anticytokine antibodies [109]. Intravenous

Table 4 Potential strategies to reduce brain dysfunction in ICU patients

\begin{tabular}{|c|c|c|}
\hline Pharmacological measures & Type of study & References \\
\hline Reduce use of benzodiazepines and opioids & Observational studies & {$[44,95]$} \\
\hline Perform daily sedation stops & $\mathrm{RCT}$ & {$[96,97]$} \\
\hline Use dexmedetomidine (versus benzodiazepines or propofol) as sedative & $\mathrm{RCT}$ & {$[46,47,98]$} \\
\hline Pain assessment: sedation - analgesia - delirium protocol & Observational studies & {$[99,100]$} \\
\hline $\begin{array}{l}\text { Prevention of metabolic disturbances (severe hypoxemia, fever, dysnatremia(s), } \\
\text { prolonged hyperglycemia...) }\end{array}$ & Observational studies & {$[4,54,57,59,101]$} \\
\hline \multicolumn{3}{|l|}{ Nonpharmacological measures } \\
\hline Sleep protocol & $\mathrm{RCT}$ (non-critical care setting) & [102] \\
\hline \multicolumn{3}{|l|}{ Reorientation and cognitively stimulating activities } \\
\hline \multicolumn{3}{|l|}{ Rehydration } \\
\hline \multicolumn{3}{|l|}{ Use of eyeglasses, magnifying lenses, and hearing aids } \\
\hline Avoid use of physical restraints & Observational studies & {$[82,103]$} \\
\hline Early mobilization & $\mathrm{RCT}$ & [104] \\
\hline
\end{tabular}


immunoglobulins, administered before cecal ligation and perforation, seem to preserve BBB integrity [110]. Regarding oxidative stress, antioxidant treatment with $\mathrm{N}$-acetylcysteine and deferoxamine prevents cognitive impairment in septic mice [52].

\section{Conclusions}

Brain dysfunction is frequent in sepsis but too often neglected, despite its dramatic impact on outcomes. Its pathophysiology is highly complex, resulting from both inflammatory and noninflammatory processes that affect all types of brain cells. The diagnosis of encephalopathy relies essentially on neurological examination, which can lead to specific neurological tests, including EEG and neuroimaging. Brain dysfunction during sepsis is frequently entwined with others factors that have to be screened systematically, including withdrawal syndrome, drugs overdose, and severe metabolic disturbances. Currently, the treatment of sepsis-associated encephalopathy mainly consists of general management of sepsis and prevention of aggravating factors, including metabolic disturbances, drug overdoses, anticholinergic medications, withdrawal syndromes, and Wernicke's encephalopathy. In the future, investigations should be undertaken to reduce the duration of brain dysfunction and to study the impact of this reduction on important health outcomes, including mortality and functional and cognitive status in survivors. Modulation of microglial activation, prevention of $\mathrm{BBB}$ alterations, and use of antioxidants represent relevant therapeutic targets that may impact significantly on neurologic outcomes.

\section{Competing interests}

The authors declare that they have no competing interests.

\section{Authors' contributions}

RS, FV, CR and TS wrote the manuscript. IFK, MW, DA, FC reviewed the manuscript. All authors read and approved the final manuscript.

\section{Author details}

'Univ Paris Diderot, Sorbonne Paris Cité, Assistance Publique-Hôpitaux de Paris, Hôpital Bichat-Claude-Bernard, Service de Réanimation Médicale et des Maladies Infectieuses, 46, rue Henri-Huchard Cedex 18, Paris 75877, France. ${ }^{2}$ Histopathologie Humaine et Modèles Animaux, Département Infection et Epidémiologie, Institut Pasteur, Paris, France. ${ }^{3}$ Univ Paris Diderot, Sorbonne Paris Cité, Assistance Publique-Hôpitaux de Paris, Hôpital BichatClaude-Bernard, Service de Radiologie, 46, rue Henri-Huchard Cedex 18Paris 75877, France. ${ }^{4}$ Réanimation medico-chirurgicale et EA4342, Hôpital Raymond Poincaré, Université de Versailles Saint-Quentin en Yvelines, Garches, France.

Received: 17 August 2012 Accepted: 30 April 2013 Published: 29 May 2013

\section{References}

1. Eidelman LA, Putterman D, Putterman C, Sprung CL: The spectrum of septic encephalopathy. Definitions, etiologies, and mortalities. JAMA 1996, 275:470-473.

2. Sprung CL, Peduzzi PN, Shatney CH, Schein RM, Wilson MF, Sheagren JN, Hinshaw LB: Impact of encephalopathy on mortality in the sepsis syndrome. The Veterans Administration systemic sepsis cooperative study group. Crit Care Med 1990, 18:801-806.

3. Milbrandt EB, Angus DC: Potential mechanisms and markers of critical illness-associated cognitive dysfunction. Curr Opin Crit Care 2005, 11:355-359

4. Jaber S, Chanques G, Altairac C, Sebbane M, Vergne C, Perrigault PF, Eledjam JJ: A prospective study of agitation in a medical-surgical ICU: incidence, risk factors, and outcomes. Chest 2005, 128:2749-2757.

5. Heymann A, Sander M, Krahne D, Deja M, Weber-Carstens S, MacGuill M, Kastrup M, Wernecke KD, Nachtigall I, Spies CD: Hyperactive delirium and blood glucose control in critically ill patients. I Int Med Res 2007, 35:666-677.

6. Ely EW, Inouye SK, Bernard GR, Gordon S, Francis J, May L, Truman B, Speroff $T$. Gautam S, Margolin R, et al: Delirium in mechanically ventilated patients: validity and reliability of the confusion assessment method for the intensive care unit (CAM-ICU). JAMA 2001, 286:2703-2710.

7. Ely EW, Shintani A, Truman B, Speroff T, Gordon SM, Harrell FE Jr, Inouye SK, Bernard GR, Dittus RS: Delirium as a predictor of mortality in mechanically ventilated patients in the intensive care unit. JAMA 2004, 291:1753-1762.

8. Tracey KJ: The inflammatory reflex. Nature 2002, 420:853-859.

9. Sharshar T, Annane D: Endocrine effects of vasopressin in critically ill patients. Best Pract Res Clin Anaesthesiol 2008, 22:265-273.

10. Semmler A, Hermann S, Mormann F, Weberpals M, Paxian SA, Okulla T, Schafers M, Kummer MP, Klockgether T, Heneka MT: Sepsis causes neuroinflammation and concomitant decrease of cerebral metabolism. J Neuroinflammation 2008, 5:38.

11. Stellwagen D, Malenka RC: Synaptic scaling mediated by glial TNF-alpha. Nature 2006, 440:1054-1059.

12. Terrando N, Monaco C, Ma D, Foxwell BM, Feldmann M, Maze M: Tumor necrosis factor-alpha triggers a cytokine cascade yielding postoperative cognitive decline. Proc Natl Acad Sci USA 2010, 107:20518-20522.

13. Terrando N, Rei Fidalgo A, Vizcaychipi M, Cibelli M, Ma D, Monaco C, Feldmann M, Maze M: The impact of IL-1 modulation on the development of lipopolysaccharide-induced cognitive dysfunction. Crit Care 2010, 14:R88.

14. Chavan SS, Huerta PT, Robbiati S, Valdes-Ferrer SI, Ochani M, Dancho M, Frankfurt M, Volpe BT, Tracey KJ, Diamond B: HMGB1 mediates cognitive impairment in sepsis survivors. Mol Med 2012, 18:930-937.

15. van Gool WA, van de Beek D, Eikelenboom P: Systemic infection and delirium: when cytokines and acetylcholine collide. Lancet 2010, 375:773-775.

16. Henry CJ, Huang Y, Wynne AM, Godbout JP: Peripheral lipopolysaccharide (LPS) challenge promotes microglial hyperactivity in aged mice that is associated with exaggerated induction of both pro-inflammatory IL1 beta and anti-inflammatory IL-10 cytokines. Brain Behav Immun 2009, 23:309-317

17. Hannestad J, Gallezot JD, Schafbauer T, Lim K, Kloczynski T, Morris ED, Carson RE, Ding YS, Cosgrove K: Endotoxin-induced systemic inflammation activates microglia: [(11)C]PBR28 positron emission tomography in nonhuman primates. Neuroimage 2012, 63:232-239.

18. Chen J, Buchanan JB, Sparkman NL, Godbout JP, Freund GG, Johnson RW: Neuroinflammation and disruption in working memory in aged mice after acute stimulation of the peripheral innate immune system. Brain Behav Immun 2008, 22:301-311.

19. Barrientos RM, Higgins EA, Biedenkapp JC, Sprunger DB, Wright-Hardesty KJ, Watkins LR, Rudy JW, Maier SF: Peripheral infection and aging interact to impair hippocampal memory consolidation. Neurobiol Aging 2006, 27:723-732.

20. Imamura $\mathrm{Y}$, Wang $\mathrm{H}$, Matsumoto $\mathrm{N}$, Muroya $\mathrm{T}$, Shimazaki J, Ogura $\mathrm{H}$, Shimazu T: Interleukin-1 beta causes long-term potentiation deficiency in a mouse model of septic encephalopathy. Neuroscience 2011, 187:63-69.

21. Cibelli M, Fidalgo AR, Terrando N, Ma D, Monaco C, Feldmann M, Takata M, Lever IJ, Nanchahal J, Fanselow MS, Maze M: Role of interleukin-1 beta in postoperative cognitive dysfunction. Ann Neurol 2010, 68:360-368.

22. Semmler A, Okulla T, Sastre M, Dumitrescu-Ozimek L, Heneka MT: Systemic inflammation induces apoptosis with variable vulnerability of different brain regions. J Chem Neuroanat 2005, 30:144-157.

23. Semmler A, Frisch C, Debeir T, Ramanathan M, Okulla T, Klockgether T, Heneka MT: Long-term cognitive impairment, neuronal loss and reduced cortical cholinergic innervation after recovery from sepsis in a rodent model. Exp Neurol 2007, 204:733-740. 
24. Weberpals M, Hermes M, Hermann S, Kummer MP, Terwel D, Semmler A, Berger M, Schafers M, Heneka MT: NOS2 gene deficiency protects from sepsis-induced long-term cognitive deficits. J Neurosci 2009, 29:14177-14184.

25. Semmler A, Widmann CN, Okulla T, Urbach H, Kaiser M, Widman G, Mormann F, Weide J, Fliessbach K, Hoeft A, et al: Persistent cognitive impairment, hippocampal atrophy and EEG changes in sepsis survivors. J Neurol Neurosurg Psychiatry 2013, 84:62-69.

26. Handa O, Stephen J, Cepinskas G: Role of endothelial nitric oxide synthase-derived nitric oxide in activation and dysfunction of cerebrovascular endothelial cells during early onsets of sepsis. Am J Physiol Heart Circ Physiol 2008, 295:H1712-1719.

27. Taccone FS, Castanares-Zapatero D, Peres-Bota D, Vincent JL, Berre J, Melot C: Cerebral autoregulation is influenced by carbon dioxide levels in patients with septic shock. Neurocrit Care 2010, 12:35-42.

28. Alexander JJ, Jacob A, Cunningham P, Hensley L, Quigg RJ: TNF is a key mediator of septic encephalopathy acting through its receptor, TNF receptor-1. Neurochem Int 2008, 52:447-456.

29. Sharshar T, Carlier R, Bernard F, Guidoux C, Brouland JP, Nardi O, de la Grandmaison GL, Aboab J, Gray F, Menon D, Annane D: Brain lesions in septic shock: a magnetic resonance imaging study. Intensive Care Med 2007, 33:798-806.

30. Fugate JE, Claassen DO, Cloft HJ, Kallmes DF, Kozak OS, Rabinstein AA: Posterior reversible encephalopathy syndrome: associated clinical and radiologic findings. Mayo Clin Proc 2010, 85:427-432

31. Bozza FA, Garteiser P, Oliveira MF, Doblas S, Cranford R, Saunders D, Jones I, Towner RA, Castro-Faria-Neto HC: Sepsis-associated encephalopathy: a magnetic resonance imaging and spectroscopy study. J Cereb Blood Flow Metab 2010, 30:440-448.

32. Pandharipande PP, Morandi A, Adams JR, Girard TD, Thompson JL, Shintani AK, Ely EW: Plasma tryptophan and tyrosine levels are independent risk factors for delirium in critically ill patients. Intensive Care Med 2009, 35:1886-1892

33. Adams Wilson JR, Morandi A, Girard TD, Thompson JL, Boomershine CS, Shintani AK, Ely EW, Pandharipande PP: The association of the kynurenine pathway of tryptophan metabolism with acute brain dysfunction during critical illness*. Crit Care Med 2012, 40:835-841.

34. Sharshar T, Annane D, de la Grandmaison GL, Brouland JP, Hopkinson NS, Francoise G: The neuropathology of septic shock. Brain Pathol 2004, $14: 21-33$

35. Sharshar T, Gray F, Lorin de la Grandmaison G, Hopkinson NS, Ross E, Dorandeu A, Orlikowski D, Raphael JC, Gajdos P, Annane D: Apoptosis of neurons in cardiovascular autonomic centres triggered by inducible nitric oxide synthase after death from septic shock. Lancet 2003, 362:1799-1805.

36. Pfister D, Siegemund M, Dell-Kuster S, Smielewski P, Ruegg S, Strebel SP, Marsch SC, Pargger H, Steiner LA: Cerebral perfusion in sepsis-associated delirium. Crit Care 2008, 12:R63.

37. Hshieh TT, Fong TG, Marcantonio ER, Inouye SK: Cholinergic deficiency hypothesis in delirium: a synthesis of current evidence. J Gerontol A Biol Sci Med Sci 2008, 63:764-772

38. Jansson A, Olin K, Yoshitake T, Hagman B, Herrington MK, Kehr J, Permert J: Effects of isoflurane on prefrontal acetylcholine release and hypothalamic Fos response in young adult and aged rats. Exp Neurol 2004, 190:535-543

39. Field RH, Gossen A, Cunningham C: Prior pathology in the basal forebrain cholinergic system predisposes to inflammation-induced working memory deficits: reconciling inflammatory and cholinergic hypotheses of delirium. J Neurosci 2012, 32:6288-6294.

40. Kadoi $Y$, Saito $S$ : An alteration in the gamma-aminobutyric acid receptor system in experimentally induced septic shock in rats. Crit Care Med 1996, 24:298-305.

41. Pavlov VA, Ochani M, Gallowitsch-Puerta M, Ochani K, Huston JM, Czura CJ, Al-Abed $Y$, Tracey $\mathrm{KJ}$ : Central muscarinic cholinergic regulation of the systemic inflammatory response during endotoxemia. Proc Natl Acad Sci USA 2006, 103:5219-5223.

42. Basler T, Meier-Hellmann A, Bredle D, Reinhart K: Amino acid imbalance early in septic encephalopathy. Intensive Care Med 2002, 28:293-298.

43. van Eijk MM, Roes KC, Honing ML, Kuiper MA, Karakus A, van der Jagt M, Spronk PE, van Gool WA, van der Mast RC, Kesecioglu J, Slooter AJ: Effect of rivastigmine as an adjunct to usual care with haloperidol on duration of delirium and mortality in critically ill patients: a multicentre, doubleblind, placebo-controlled randomised trial. Lancet 2010, 376:1829-1837.

44. Pandharipande P, Shintani A, Peterson J, Pun BT, Wilkinson GR, Dittus RS, Bernard GR, Ely EW: Lorazepam is an independent risk factor for transitioning to delirium in intensive care unit patients. Anesthesiology 2006, 104:21-26.

45. Pandharipande PP, Sanders RD, Girard TD, McGrane S, Thompson JL, Shintani AK, Herr DL, Maze M, Ely EW: Effect of dexmedetomidine versus lorazepam on outcome in patients with sepsis: an a priori-designed analysis of the MENDS randomized controlled trial. Crit Care 2010, 14:R38.

46. Pandharipande PP, Pun BT, Herr DL, Maze M, Girard TD, Miller RR, Shintani AK, Thompson JL, Jackson JC, Deppen SA, et al: Effect of sedation with dexmedetomidine vs lorazepam on acute brain dysfunction in mechanically ventilated patients: the MENDS randomized controlled trial. JAMA 2007, 298:2644-2653.

47. Jakob SM, Ruokonen E, Grounds RM, Sarapohja T, Garratt C, Pocock SJ, Bratty JR, Takala J: Dexmedetomidine vs midazolam or propofol for sedation during prolonged mechanical ventilation: two randomized controlled trials. JAMA 2012, 307:1151-1160

48. Dahmani S, Rouelle D, Gressens P, Mantz J: Effects of dexmedetomidine on hippocampal focal adhesion kinase tyrosine phosphorylation in physiologic and ischemic conditions. Anesthesiology 2005, 103:969-977.

49. Dahmani S, Rouelle D, Gressens P, Mantz J: Characterization of the postconditioning effect of dexmedetomidine in mouse organotypic hippocampal slice cultures exposed to oxygen and glucose deprivation. Anesthesiology 2010, 112:373-383.

50. Degos V, Charpentier TL, Chhor V, Brissaud O, Lebon S, Schwendimann L, Bednareck N, Passemard S, Mantz J, Gressens P: Neuroprotective effects of dexmedetomidine against glutamate agonist-induced neuronal cell death are related to increased astrocyte brain-derived neurotrophic factor expression. Anesthesiology 2013, 118:1123-1132.

51. Barichello T, Fortunato JJ, Vitali AM, Feier G, Reinke A, Moreira JC, Quevedo J, Dal-Pizzol F: Oxidative variables in the rat brain after sepsis induced by cecal ligation and perforation. Crit Care Med 2006, 34:886-889.

52. Barichello T, Machado RA, Constantino L, Valvassori SS, Reus GZ, Martins MR, Petronilho F, Ritter C, Quevedo J, Dal-Pizzol F: Antioxidant treatment prevented late memory impairment in an animal model of sepsis. Crit Care Med 2007, 35:2186-2190

53. Comim CM, Barichello T, Grandgirard D, Dal-Pizzol F, Quevedo J, Leib SL, Comim CM, Barichello T, Grandgirard D, Dal-Pizzol F, Quevedo J, Leib SL: Caspase-3 mediates in part hippocampal apoptosis in sepsis. Mol Neurobiol 2013, 47:39-48.

54. Polito A, Brouland JP, Porcher R, Sonneville R, Siami S, Stevens RD, Guidoux C, Maxime V, de la Grandmaison GL, Chretien FC, et al: Hyperglycaemia and apoptosis of microglial cells in human septic shock. Crit Care 2011, 15:R131

55. McGrane S, Girard TD, Thompson JL, Shintani AK, Woodworth A, Ely EW Pandharipande PP: Procalcitonin and C-reactive protein levels at admission as predictors of duration of acute brain dysfunction in critically ill patients. Crit Care 2011, 15:R78.

56. van den Boogaard M, Kox M, Quinn KL, van Achterberg T, van der Hoeven JG, Schoonhoven L, Pickkers P: Biomarkers associated with delirium in critically ill patients and their relation with long-term subjective cognitive dysfunction; indications for different pathways governing delirium in inflamed and noninflamed patients. Crit Care 2011, 15:R297.

57. Sonneville R, den Hertog HM, Guiza F, Gunst J, Derese I, Wouters PJ, Brouland JP, Polito A, Gray F, Chretien F, et al: Impact of hyperglycemia on neuropathological alterations during critical illness. J Clin Endocrinol Metab 2012, 97:2113-2123.

58. Hopkins RO, Suchyta MR, Snow GL, Jephson A, Weaver LK, Orme JF: Blood glucose dysregulation and cognitive outcome in ARDS survivors. Brain Inj 2010, 24:1478-1484.

59. Mikkelsen ME, Christie JD, Lanken PN, Biester RC, Thompson BT, Bellamy SL, Localio AR, Demissie E, Hopkins RO, Angus DC: The ARDS Cognitive Outcomes Study (ACOS): long-term neuropsychological function in acute lung injury survivors. Am J Respir Crit Care Med 2012, 185:1307-15.

60. Janz DR, Abel TW, Jackson JC, Gunther ML, Heckers S, Ely EW: Brain autopsy findings in intensive care unit patients previously suffering from delirium: a pilot study. J Crit Care 2010, 25(538):e537-512.

61. Girard TD, Jackson JC, Pandharipande PP, Pun BT, Thompson JL, Shintani AK, Gordon SM, Canonico AE, Dittus RS, Bernard GR, Ely EW: Delirium as a 
predictor of long-term cognitive impairment in survivors of critical illness. Crit Care Med 2010, 38:1513-1520.

62. Sharshar T, Porcher R, Siami S, Rohaut B, Bailly-Salin J, Hopkinson NS, Clair B, Guidoux C, lacobone E, Sonneville R, et al: Brainstem responses can predict death and delirium in sedated patients in intensive care unit. Crit Care Med 2011, 39:1960-1967.

63. Engelhard K, Werner C, Eberspacher E, Bachl M, Blobner M, Hildt E, Hutzler $P$, Kochs $E$ : The effect of the alpha 2-agonist dexmedetomidine and the $\mathrm{N}$-methyl-D-aspartate antagonist $\mathrm{S}(+)$-ketamine on the expression of apoptosis-regulating proteins after incomplete cerebral ischemia and reperfusion in rats. Anesth Analg 2003, 96:524-531. table of contents.

64. Pandharipande PP, Sanders RD, Girard TD, McGrane S, Thompson JL, Shintani AK, Herr DL, Maze M, Ely EW: Effect of dexmedetomidine versus lorazepam on outcome in patients with sepsis: an a priori-designed analysis of the MENDS randomized controlled trial. Crit Care 2007, 14:R38.

65. Annane D, Trabold F, Sharshar T, Jarrin I, Blanc AS, Raphael JC, Gajdos P: Inappropriate sympathetic activation at onset of septic shock: a spectral analysis approach. Am J Respir Crit Care Med 1999, 160:458-465.

66. lacobone E, Bailly-Salin J, Polito A, Friedman D, Stevens RD, Sharshar T: Sepsis-associated encephalopathy and its differential diagnosis. Crit Care Med 2009, 37:S331-336.

67. Bergeron N, Dubois MJ, Dumont M, Dial S, Skrobik Y: Intensive Care Delirium Screening Checklist: evaluation of a new screening tool. Intensive Care Med 2001, 27:859-64.

68. Piazza O, Russo E, Cotena S, Esposito G, Tufano R: Elevated S100B levels do not correlate with the severity of encephalopathy during sepsis. $\mathrm{Br}$ J Anaesth 2007, 99:518-521.

69. Nguyen DN, Spapen H, Su F, Schiettecatte J, Shi L, Hachimi-Idrissi S, Huyghens L: Elevated serum levels of S-100beta protein and neuronspecific enolase are associated with brain injury in patients with severe sepsis and septic shock. Crit Care Med 2006, 34:1967-1974.

70. Bartynski WS, Boardman JF, Zeigler ZR, Shadduck RK, Lister J: Posterior reversible encephalopathy syndrome in infection, sepsis, and shock. AJNR Am J Neuroradiol 2006, 27:2179-2190.

71. Morandi A, Rogers BP, Gunther ML, Merkle K, Pandharipande P, Girard TD, Jackson JC, Thompson J, Shintani AK, Geevarghese S, et al: The relationship between delirium duration, white matter integrity, and cognitive impairment in intensive care unit survivors as determined by diffusion tensor imaging: the VISIONS prospective cohort magnetic resonance imaging study*. Crit Care Med 2012, 40:2182-2189.

72. Gunther ML, Morandi A, Krauskopf E, Pandharipande P, Girard TD, Jackson JC, Thompson J, Shintani AK, Geevarghese S, Miller RR 3rd, et al: The association between brain volumes, delirium duration, and cognitive outcomes in intensive care unit survivors: the VISIONS cohort magnetic resonance imaging study*. Crit Care Med 2012, 40:2022-2032.

73. Oddo M, Carrera E, Claassen J, Mayer SA, Hirsch LJ: Continuous electroencephalography in the medical intensive care unit. Crit Care Med 2009, 37:2051-2056.

74. Foreman B, Claassen J, Abou Khaled K, Jirsch J, Alschuler DM, Wittman J, Emerson RG, Hirsch $\sqcup$ : Generalized periodic discharges in the critically ill: a case-control study of 200 patients. Neurology 2012, 79:1951-1960.

75. Watson PL, Shintani AK, Tyson R, Pandharipande PP, Pun BT, Ely EW: Presence of electroencephalogram burst suppression in sedated, critically ill patients is associated with increased mortality. Crit Care Med 2008, 36:3171-3177.

76. Young GB, Bolton CF, Archibald YM, Austin TW, Wells GA: The electroencephalogram in sepsis-associated encephalopathy. J Clin Neurophysiol 1992, 9:145-152

77. Ong C, Gilmore E, Claassen J, Foreman B, Mayer SA: Impact of prolonged periodic epileptiform discharges on coma prognosis. Neurocrit Care 2012, 17:39-44.

78. Awissi DK, Lebrun G, Coursin DB, Riker RR, Skrobik Y: Alcohol withdrawal and delirium tremens in the critically ill: a systematic review and commentary. Intensive Care Med 2013, 39:16-30.

79. Sechi G, Serra A: Wernicke's encephalopathy: new clinical settings and recent advances in diagnosis and management. Lancet Neurol 2007, 6:442-455.

80. Lucidarme O, Seguin A, Daubin C, Ramakers M, Terzi N, Beck P, Charbonneau P, du Cheyron D: Nicotine withdrawal and agitation in ventilated critically ill patients. Crit Care 2010, 14:R58.
81. Zaal IJ, Spruyt CF, Peelen LM, van Eijk MM, Wientjes R, Schneider MM, Kesecioglu J, Slooter AJ: Intensive care unit environment may affect the course of delirium. Intensive Care Med 2012, 39:481-488.

82. MCPherson JA, Wagner CE, Boehm LM, Hall JD, Johnson DC, Miller LR, Burns KM, Thompson JL, Shintani AK, Ely EW, Pandharipande PP: Delirium in the cardiovascular ICU: exploring modifiable risk factors. Crit Care Med 2012, 41:405-413.

83. Sonneville R, Mirabel M, Hajage D, Tubach F, Vignon P, Perez P, Lavoue S, Kouatchet A, Pajot O, Dessap AM, et al: Neurologic complications and outcomes of infective endocarditis in critically ill patients: the ENDOcardite en REAnimation prospective multicenter study. Crit Care Med 2011, 39:1474-1481.

84. Klein I, lung B, Labreuche J, Hess A, Wolff M, Messika-Zeitoun D, Lavallee P, Laissy JP, Leport C, Duval X: Cerebral microbleeds are frequent in infective endocarditis: a case-control study. Stroke 2009, 40:3461-3465.

85. Pisani MA, Kong SY, KasI SV, Murphy TE, Araujo KL, Van Ness PH: Days of delirium are associated with 1-year mortality in an older intensive care unit population. Am J Respir Crit Care Med 2009, 180:1092-1097.

86. Milbrandt EB, Deppen S, Harrison PL, Shintani AK, Speroff T, Stiles RA Truman B, Bernard GR, Dittus RS, Ely EW: Costs associated with delirium in mechanically ventilated patients. Crit Care Med 2004, 32:955-962.

87. Iwashyna TJ, Ely EW, Smith DM, Langa KM: Long-term cognitive impairment and functional disability among survivors of severe sepsis. JAMA 2010, 304:1787-1794

88. Hopkins RO, Herridge MS: Quality of life, emotional abnormalities, and cognitive dysfunction in survivors of acute lung injury/acute respiratory distress syndrome. Clin Chest Med 2006, 27:679-689. abstract x.

89. Hopkins RO, Jackson JC: Assessing neurocognitive outcomes after critical illness: are delirium and long-term cognitive impairments related? Curr Opin Crit Care 2006, 12:388-394.

90. Hopkins RO, Jackson JC: Short- and long-term cognitive outcomes in intensive care unit survivors. Clin Chest Med 2009, 30:143-153. ix.

91. Boer KR, van Ruler O, van Emmerik AA, Sprangers MA, de Rooij SE, Vroom $M B$, de Borgie CA, Boermeester MA, Reitsma JB: Factors associated with posttraumatic stress symptoms in a prospective cohort of patients after abdominal sepsis: a nomogram. Intensive Care Med 2008, 34:664-674.

92. Girard TD, Pandharipande PP, Ely EW: Delirium in the intensive care unit. Crit Care 2008, 12(Suppl 3):S3

93. Spapen H, Nguyen DN, Troubleyn J, Huyghens L, Schiettecatte J: Drotrecogin alfa (activated) may attenuate severe sepsis-associated encephalopathy in clinical septic shock. Crit Care 2010, 14:R54.

94. Schelling G, Roozendaal B, Krauseneck T, Schmoelz M, DEQ D, Briegel J: Efficacy of hydrocortisone in preventing posttraumatic stress disorde following critical illness and major surgery. Ann N Y Acad Sci 2006, 1071:46-53.

95. Ouimet S, Kavanagh BP, Gottfried SB, Skrobik Y: Incidence, risk factors and consequences of ICU delirium. Intensive Care Med 2007, 33:66-73.

96. Kress JP, Pohlman AS, O'Connor MF, Hall JB: Daily interruption of sedative infusions in critically ill patients undergoing mechanical ventilation. $N$ Engl J Med 2000, 342:1471-1477.

97. Girard TD, Kress JP, Fuchs BD, Thomason JW, Schweickert WD, Pun BT Taichman DB, Dunn JG, Pohlman AS, Kinniry PA, et al: Efficacy and safety of a paired sedation and ventilator weaning protocol for mechanically ventilated patients in intensive care (Awakening and Breathing Controlled trial): a randomised controlled trial. Lancet 2008, 371:126-134.

98. Riker RR, Shehabi Y, Bokesch PM, Ceraso D, Wisemandle W, Koura F, Whitten P, Margolis BD, Byrne DW, Ely EW, Rocha MG: Dexmedetomidine vs midazolam for sedation of critically ill patients: a randomized trial. JAMA 2009, 301:489-499.

99. Payen JF, Bosson JL, Chanques G, Mantz J, Labarere J: Pain assessment is associated with decreased duration of mechanical ventilation in the intensive care unit: a post Hoc analysis of the DOLOREA study. Anesthesiology 2009, 111:1308-1316.

100. Awissi DK, Begin C, Moisan J, Lachaine J, Skrobik Y: I-SAVE study: impact of sedation, analgesia, and delirium protocols evaluated in the intensive care unit: an economic evaluation. Ann Pharmacother 2012, 46:21-28.

101. Woods JC, Mion LC, Connor JT, Viray F, Jahan L, Huber C, McHugh R, Gonzales JP, Stoller JK, Arroliga AC: Severe agitation among ventilated medical intensive care unit patients: frequency, characteristics and outcomes. Intensive Care Med 2004, 30:1066-1072 
102. Inouye SK, Bogardus ST Jr, Charpentier PA, Leo-Summers L, Acampora D, Holford TR, Cooney LM Jr: A multicomponent intervention to prevent delirium in hospitalized older patients. N Engl J Med 1999, 340:669-676.

103. Micek ST, Anand NJ, Laible BR, Shannon WD, Kollef MH: Delirium as detected by the CAM-ICU predicts restraint use among mechanically ventilated medical patients. Crit Care Med 2005, 33:1260-1265.

104. Schweickert WD, Pohlman MC, Pohlman AS, Nigos C, Pawlik AJ, Esbrook CL, Spears L, Miller M, Franczyk M, Deprizio D, et al: Early physical and occupational therapy in mechanically ventilated, critically ill patients: a randomised controlled trial. Lancet 2009, 373:1874-1882.

105. Kadoi Y, Goto F: Selective inducible nitric oxide inhibition can restore hemodynamics, but does not improve neurological dysfunction in experimentally-induced septic shock in rats. Anesth Analg 2004, 99:212-220

106. Esen F, Erdem T, Aktan D, Orhan M, Kaya M, Eraksoy H, Cakar N, Telci L: Effect of magnesium sulfate administration on blood-brain barrier in a rat model of intraperitoneal sepsis: a randomized controlled experimental study. Crit Care 2005, 9:R18-23.

107. Toklu HZ, Uysal MK, Kabasakal L, Sirvanci S, Ercan F, Kaya M: The effects of riluzole on neurological, brain biochemical, and histological changes in early and late term of sepsis in rats. J Surg Res 2009, 152:238-248.

108. Avtan SM, Kaya M, Orhan N, Arslan A, Arican N, Toklu AS, Gurses C, Elmas I, Kucuk M, Ahishali B: The effects of hyperbaric oxygen therapy on bloodbrain barrier permeability in septic rats. Brain Res 2011, 1412:63-72.

109. Wratten ML: Therapeutic approaches to reduce systemic inflammation in septic-associated neurologic complications. Eur J Anaesthesio/ Supp/ 2008, 42:1-7.

110. Esen F, Senturk E, Ozcan PE, Ahishali B, Arican N, Orhan N, Ekizoglu O, Kucuk $M$, Kaya M: Intravenous immunoglobulins prevent the breakdown of the blood-brain barrier in experimentally induced sepsis. Crit Care Med 2012, 40:1214-1220.

doi:10.1186/2110-5820-3-15

Cite this article as: Sonneville et al:: Understanding brain dysfunction in sepsis. Annals of Intensive Care 2013 3:15.

\section{Submit your manuscript to a SpringerOpen ${ }^{\circ}$ journal and benefit from:}

- Convenient online submission

$\checkmark$ Rigorous peer review

- Immediate publication on acceptance

- Open access: articles freely available online

- High visibility within the field

- Retaining the copyright to your article

Submit your next manuscript at $\gg$ springeropen.com 